
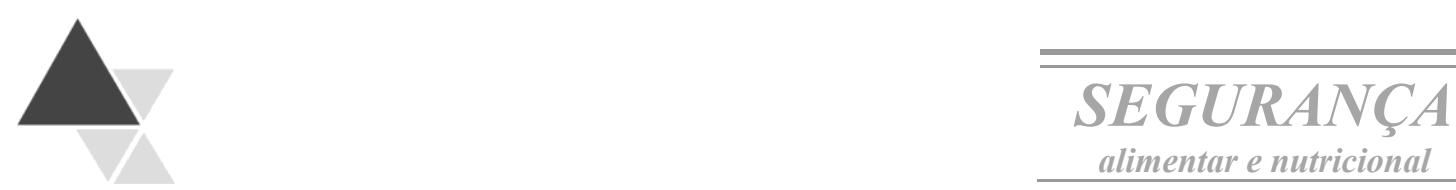

\title{
A Alimentação Escolar como Fator de Desenvolvimento Local por meio do Apoio aos Agricultores Familiares ${ }^{1}$
}

\author{
Maria Elena Turpin ${ }^{2}$
}

Este artigo busca avaliar a atual contribuição e as potencialidades do Programa Nacional de Alimentação Escolar - PNAE, como instrumento para o Desenvolvimento Local - DL, por meio de apoio aos agricultores familiares, considerando-se a magnitude do Programa e a destacada importância econômica e social desse segmento nas ações locais para o desenvolvimento. A integração de políticas públicas com o foco na agricultura familiar pode ser um modelo efetivo de redução da desigualdade social em uma região. A pesquisa revela diversos mecanismos utilizados pelos municípios nos quais a alimentação escolar é fator determinante de apoio à agricultura familiar, estímulo esse baseado em três aspectos presentes na legislação do PNAE há vários anos: exigência ao respeito à vocação agrícola e hábitos alimentares regionais; compras dentro dos limites geográficos regionais; e uso de produtos in natura, típicos dessa produção. Entre os mecanismos destacam-se os de cunho comercial e de fortalecimento institucional e organizacional da produção familiar pesquisados nas experiências do Prêmio Gestor Eficiente da Merenda Escolar organizado pela Organização Não-governamental Ação Fome Zero.

Palavras-chave: agricultura familiar e campesinato, empreendedorismo, integração e exclusão, políticas públicas para agricultura familiar.

\section{The School Feeding as a Factor for Local Development, by Means of Supporting Family Farmers}

This article evaluates the current contribution and potentialities of the National School Feeding Program (PNAE - Programa Nacional de Alimentação Escolar) as an instrument for local development by means of supporting family farmers, considering the magnitude of the Program and the great economic and social importance of this segment in local actions for development. The integrated public policies focusing the family-based agriculture can be an effective model towards the reduction of social inequality in a region.The research showed some mechanisms used by the municipalities in which the School Feeding is a determinant factor of supporting the family-based agriculture, which incentive is based on three aspects of the PNAE 's legislation in several years: exigency in respecting the regional agricultural vocation and the alimentary habits of the population; purchases of goods inside the regional geographical limits; and use of natural products, typical of that agriculture. Among the mechanisms are pointed out the commercial ones and the institutional and organizational strengthening of the family production according to data base of the 2006 Efficient Manager of School Feeding Award, organized by the Non-Governmental Institution Ação Fome Zero.

Key-words: family-based agriculture and settlement, entrepreneurship, integration and exclusion, public policies for the family-based agriculture.

\footnotetext{
${ }^{1}$ Este artigo é baseado na dissertação intitulada "A Alimentação Escolar como Vetor de Desenvolvimento Local e Garantia de Segurança Alimentar e Nutricional” (Instituto de Economia da UNICAMP), orientada pelo Prof. Dr. Walter Belik.

${ }^{2}$ Mestre em Desenvolvimento Econômico-área de concentração: Economia Agrícola e Agrária. Analista de Projetos da ONG Ação Fome Zero. Rua Itapiru, n.465, apto. 31. CEP04143-010, São Paulo, SP. E-mail: nipmel@yahoo.com.br
} 


\section{Introdução}

A alimentação escolar no Brasil iniciou-se a partir de iniciativas isoladas da sociedade civil e posteriormente por meio dos esforços de alguns estados e municípios até se chegar a um Programa de abrangência nacional, coordenado pelo Governo Federal. Desde sua origem, a preocupação que motivava pais, professores, funcionários e diretores de escolas e outros agentes privados, e que alicerçou a concepção básica do Programa público, foi a desnutrição das crianças.

A partir das primeiras linhas de orientação nacional sobre o tema nos anos 30, mesmo que não aplicada em bases práticas, estudiosos e profissionais envolvidos com o assunto já definiam cardápios adequados às diversas regiões do país, preconizando o emprego de alimentos regionais, o que visava enriquecer a base nutritiva da alimentação dos escolares, mas que também viria a se constituir no embrião do apoio à pequena produção local ${ }^{[1]}$.

A criação do Programa Nacional de Alimentação Escolar - PNAE em 1954 no Ministério da Saúde, e formalizada em 1955 no Ministério da Educação e Cultura por meio do decreto $\mathrm{n}^{\mathrm{o}} 37.106 / 55$, embora não tivesse como função central erradicar a desnutrição nem o de ser um mecanismo indutor de Desenvolvimento Local - DL, incorporou essas questões no marco legal da sua constituição ${ }^{[2]}$. Seus objetivos principais visavam essencialmente a redução da desnutrição do escolar e a melhoria dos hábitos alimentares. Atualmente o PNAE é coordenado pelo Fundo Nacional de
Desenvolvimento da Educação - FNDE, autarquia vinculada ao Ministério da Educação.

Desde então, a merenda escolar tem contribuído, principalmente após a sua descentralização, para incrementar a alimentação de alunos da rede pública e filantrópica ${ }^{3}$ em todo o país e ampliado o potencial de incentivo à pequena produção familiar local. O esforço de municipalização previa a melhoria da qualidade alimentar por meio de diretrizes a serem aplicadas nas localidades, que ao mesmo tempo levavam ao fortalecimento desse segmento.

Em 2008, o PNAE movimentou um montante na ordem de $\mathrm{R} \$ 1,5$ bilhão, beneficiando mais de 34,6 milhões de estudantes ${ }^{[3]}$ que fizeram pelo menos uma refeição ao dia. Pode-se considerá-lo o maior Programa de suplementação alimentar da América Latina, tendo em vista o tempo de atuação, a continuidade, o compromisso constitucional desde 1988, o caráter universal, o número de alunos atendidos e o volume de investimentos já realizados. Seu objetivo central é "atender às necessidades nutricionais dos alunos. Durante sua permanência em sala de aula e à formação de hábitos alimentares saudáveis, contribuindo para o seu crescimento, desenvolvimento, aprendizado e rendimento escolar", mas tem como uma de suas diretrizes "o apoio ao desenvolvimento sustentável, com incentivos para aquisição de gêneros alimentícios diversificados, preferencialmente produzidos e comercializados em âmbito local" ${ }^{[4]}$.

\footnotetext{
3 Desde que cadastradas no Censo Escolar e registradas no Conselho Nacional de Assistência Social.
} 
Por outro lado, as tradicionais políticas de desenvolvimento sócio-econômico não têm sido capazes de acabar com as desigualdades regionais, perpetuando a pobreza rural e urbana até os dias atuais. O enfoque territorial do Desenvolvimento Local tem sido estudado há cerca de 40 anos, mas foi a partir da década de 90 que entrou definitivamente na pauta de formulação e aplicação de políticas públicas, em âmbito municipal e intermunicipal ${ }^{[5]}$.

$\mathrm{Na}$ formulação da política de Desenvolvimento Local considera-se a agricultura familiar como um segmento a ser dinamizado. Embora a produção familiar responda atualmente por $38 \%$ do valor bruto da produção agropecuária nacional e ocupe $77 \%$ da mão-de-obra do campo ${ }^{[6]}$ muitas vezes esses produtores não têm acesso às redes comerciais, sendo necessária a construção de "pontes" que os vinculem a outros agentes econômicos e sociais. A chamada "demanda institucional" constitui-se em um dos elementos que podem ser utilizados, de forma coordenada com outras ações, a fim de garantir mercado para essa produção.

A partir desse panorama geral, considerando a vinculação histórica do Programa Nacional de Alimentação Escolar ao apoio à agricultura familiar e à necessidade de aprimoramento dos mecanismos de Desenvolvimento Local e Territorial ligados a esse segmento que tradicionalmente esteve à margem das políticas setoriais e do circuito comercial comandado pelas grandes empresas, este artigo pretende contribuir para a identificação de mecanismos que a gestão da alimentação escolar nos municípios não só utiliza para melhorar o atendimento às crianças, mas que, ao mesmo tempo, ajudam a promover o desenvolvimento local por meio do apoio à agricultura familiar.

Para a identificação desses mecanismos utilizou-se neste artigo prioritariamente a base de dados da $3^{\mathrm{a}}$ edição do Prêmio Gestor Eficiente da Merenda Escolar ${ }^{4}$ 2006, ano base 2005, desenvolvido e coordenado pela ONG Ação Fome Zero, que, teoricamente, reúne dados sobre as melhores gestões do PNAE. Em 2006 o Prêmio obteve 610 inscrições de Prefeituras. O formulário de inscrição traz, entre outras, perguntas sobre compras da produção local pela Prefeitura para abastecer a merenda escolar, identificando o tipo de organização produtiva (produtores individuais ou reunidos em associações/cooperativas), os valores e os produtos adquiridos; sobre a participação no Programa de Aquisição de Alimentos da Agricultura Familiar - PAA, incluindo também os valores e os produtos adquiridos; e possíveis Programas/projetos municipais de apoio à pequena produção.

Foram utilizados também documentos da Companhia Nacional de Abastecimento CONAB e do Ministério de Desenvolvimento Social e Combate à Fome - MDS sobre o PAA, que visa fortalecer esse segmento a partir da compra de seus produtos. Além dessas fontes, foram utilizados depoimentos e declarações de gestores públicos e agricultores familiares envolvidos nos projetos de desenvolvimento local a partir da merenda escolar.

\footnotetext{
${ }^{4}$ Iniciativa da ONG Ação Fome Zero, o Prêmio tem avaliado, desde 2004, a gestão do PNAE realizada pelas Entidades Executoras municipais que se inscreveram, e gerado informação e disseminação de conhecimento a respeito do tema. Tem como uma de suas categorias de premiação o Desenvolvimento Local, em que foram vencedoras as Prefeituras de Quissamã/RJ, de Concórdia/SC e de Fernandes Pinheiro/PR, nos anos de 2004, 2005 e 2006, respectivamente.
} 


\section{O novo paradigma do desenvolvimento e a importância da agricultura familiar}

Entre os especialistas, muitos consideram que as bases do processo do desenvolvimento econômico regional mudaram profundamente a partir da última década, motivadas, após a crise econômica pela qual passaram os países ocidentais nos anos 70 e 80, pela ruptura do modelo de acumulação capitalista, de base fordista, e passagem para uma nova modalidade conhecida como o paradigma da flexibilidade. O estudo do Desenvolvimento Local começou a aparecer como um novo paradigma do desenvolvimento.

A concepção anterior, antes de meados dos anos 70, apresentava um caráter mais setorial e uma estratégia de planejamento do território coordenada por um poder central que tentava desenvolver determinados espaços por meio do direcionamento dos fluxos de investimento e da geração de empregos, criando pólos de crescimento. Segundo Benko ${ }^{[5]}$, nos anos 90 as teorias de desenvolvimento regional foram reconsideradas, não só pelas mudanças do sistema produtivo, mas porque a economia se mundializou e globalizou, aguçando as concorrências entre os lugares e os Estados e desenhando "novos territórios em rede na escala planetária".

No novo período de transição, o regime de acumulação foi acompanhado por mudanças fundamentais nos modos de produção e de consumo, nas transações e nos mecanismos institucionais de regulação das relações sociais para fazer frente à redução da demanda provocada não só pelos choques inflacionários, mas pela saturação dos mercados para os bens de consumo em massa e redução dos investimentos. Tais inovações induziram uma reestruturação espacial de toda a sociedade e redefinição do conteúdo ideológico dos espaços, fundamentadas em princípios de flexibilidade e diversificação não só dos produtos e processos de produção, por meio das mudanças tecnológicas e organizacionais, como também na regulação das relações de trabalho, representando uma nova regulação social. Nessa linha, a nova dinâmica dos espaços econômicos apresentava como elementos centrais a expansão das indústrias de alta tecnologia, as economias de serviços e as atividades artesanais e das micro e pequenas empresas ${ }^{[5]}$.

Assim, o Desenvolvimento Local surgiu na literatura econômica associado aos estudos sobre os fatores de localização do sistema produtivo, com o objetivo de elucidar os mecanismos que explicavam ou determinavam tanto os processos de concentração das atividades produtivas, como os que faziam com que uma determinada localidade exibisse um maior dinamismo e capacidade competitiva em relação a outras. A partir daí e com base em conceitos do modelo insumo-produto, surgiram os primeiros trabalhos de planejamento e políticas regionais ${ }^{[7,8]}$.

Um ponto de destaque nessa discussão foi, e ainda é, a questão do papel do Estado e o conflito entre políticas centralizadas e descentralizadas. Os chamados localistas defendem a descentralização completa e a autonomia total de ações em nível local em contraposição à corrente que considera essencial a presença do Estado coordenando 
um projeto nacional de Desenvolvimento Local, no qual se garanta a eqüidade entre as diferentes regiões e a necessária desconcentração de renda do país.

No conceito localista é atribuída ênfase ao caráter localizado do desenvolvimento econômico, cujo eixo é urbano-rural, e em que há particular preocupação, tanto com a competitividade das pequenas e médias empresas, como agentes, quanto com a descentralização como marco político-administrativo. Neste, há três elementos que explicam o caráter localizado: as externalidades positivas, entendidas como as economias externas que contribuem para a redução dos custos; o aprendizado, que se constitui na construção de uma "atmosfera de conhecimento coletivo" geradora de inovações que levam à competitividade; e a governança, constituindo-se nas rotinas, regras, costumes e valores institucionais de uma região ou território, que ganham legitimidade pela participação social, efetivada pela descentralização do processo ${ }^{[9]}$.

Putnan ${ }^{[10]}$ destaca o papel das instituições e da formação do capital social ${ }^{5}$ como um dos elementos centrais no desenvolvimento econômico regional. Usando o exemplo da experiência do norte da Itália, que se tornou uma referência nos anos 90 para formulação de estratégias de Desenvolvimento Local e Regional, Putnan ${ }^{[10]}$ afirma que a incapacidade para cooperar com o mútuo proveito é a principal razão dos insucessos de algumas regiões. Segundo o autor, para se chegar à cooperação é necessário conquistar a confiança mútua, que ocorre quando os agentes envolvidos assumem compromissos baseados em regras pré-estabelecidas. Tal cooperação se dá mais facilmente em comunidades que tenham herdado um bom "estoque" de capital social (regras de reciprocidade e sistemas de participação cívica) desenvolvido ao longo das gerações.

A outra linha de pensamento considera esses critérios de desenvolvimento da região extremamente utópicos ao subestimar os limites colocados à regulação local e o papel do Estado. Conforme aponta Brandão [11], há que se ter em conta que qualquer sistema de produção, em qualquer escala, é constituído por um ambiente de concorrência oligopólica, onde dominam o grande capital e o capital financeiro, e que está sujeito a condições não tão propícias à cooperação como, por exemplo, barreiras à entrada nos setores principais. Nas propaladas vantagens de aglomeração e de proximidade como fontes de conhecimento e aprendizagem entre os atores locais, deve-se considerar que muitas vezes o comando maior desses processos está fora do espaço sob análise. Segundo o autor, desconsiderar o papel do Estado, das variáveis macroeconômicas, e acreditar que desenvolvimento está aliado a uma idéia de calma, tranqüilidade e equilíbrio, não leva ao fortalecimento da economia local e regional de forma homogênea em âmbito nacional. No seu entendimento, o desenvolvimento é o "alargamento dos horizontes de possibilidades" em um uma

\footnotetext{
${ }^{5} \mathrm{O}$ capital social é definido pelas características da organização social em relação à confiança, normas e sistemas que contribuem para aumentar a eficiência da sociedade, facilitando as ações coordenadas ${ }^{[10]}$.
} 
atmosfera de tensão, de "distorção de correlação de forças", quebrando com a dominação e reprodução do poder tradicional.

As duas linhas podem explicar o desenvolvimento do segmento em estudo. Há muito pouco tempo a agricultura familiar começou a ser reconhecida pelas políticas públicas como um segmento que merecesse apoio. Até meados da década de 90 o caráter concentrador da modernização agrícola implementada por meio da revolução verde impediu o desenvolvimento da agricultura familiar. O papel do Estado foi decisivo intervindo no sentido de privilegiar a produção capitalista de origem urbano-industrial, cuja base técnica assentava-se no latifúndio, na monocultura e o uso de produtos agroquímicos e na mecanização. Nesse modelo, vários agricultores familiares foram excluídos, gerando o êxodo rural e a formação dos grandes bolsões de pobreza urbanos.

Desde o início do Sistema Nacional de Crédito Rural, em 1965, a destinação do crédito privilegiava médios e grandes proprietários (devido às exigências de garantia e excesso de burocracia) da região centro-sul do país e chegava a subsidiar mais da metade do valor da maquinaria agrícola ${ }^{[12]}$.

No âmbito do pequeno produtor rural, as políticas de crédito, que tradicionalmente não incluíam essa categoria, começaram a entrar na pauta governamental a partir da reforma da Constituição em 1987, com a elaboração de uma proposta de lei Agrícola pelos movimentos sindicais, que incluía uma política de crédito voltada para a agricultura familiar. Em 1994, o Ministério da Agricultura e do Abastecimento criou o Programa de
Valorização da Pequena Produção Rural PROVAP, crédito de investimento subsidiado para os agricultores familiares, que viria a ser base para a elaboração do Programa Nacional de Fortalecimento da Agricultura Familiar PRONAF, em $1995^{[13]}$.

Segundo Silva ${ }^{[14]}$, o PRONAF foi aceito na esfera governamental devido à comprovação da capacidade da agricultura familiar em absorver mão-de-obra, transformando-se em opção privilegiada para combater parte dos problemas sociais urbanos provocados pelo desemprego rural.

Dados apresentados pelo $\mathrm{MDA}^{6}$, em 2003, revelaram que a participação do agronegócio familiar no PIB - Produto Interno Bruto nacional chegou a $10,1 \%$, o que correspondeu a um valor adicionado de R\$ 156,6 bilhões. Os estabelecimentos familiares, dispondo de apenas 30\% da área, foram responsáveis por quase $38 \%$ do Valor Bruto da Produção - VBP da agropecuária nacional e, na produção de feijão, leite, milho, mandioca, suínos, cebola, banana e fumo, essa proporção chegou à cerca de 50\%. Demonstraram ser grandes empregadores e eficientes na atividade produtiva, tendo sido responsáveis por praticamente $77 \%$ do pessoal ocupado no meio rural brasileiro e obtido renda total por hectare/ano 2,4 vezes maior que a dos demais (em imóveis cuja área média é 17 vezes menor que a dos estabelecimentos patronais) ${ }^{[6]}$.

Além disso, a agricultura familiar, apesar de sua heterogeneidade interna, foi capaz de assegurar a independência do modelo de produção capitalista, basicamente por não haver separação total entre o capital e os

${ }^{6}$ Estudo realizado pela Fundação Instituto de Pesquisas - FIPE. 
demais fatores de produção; pelo trabalho não ser totalmente alienado; pela subordinação do capital não estar no mesmo patamar que os demais setores produtivos; e pela divisão social do trabalho não estar consolidada, como aponta Kühn ${ }^{[15]}$. Essas características são ainda mais valorizadas ao se constatar a insustentabilidade do modo de produção capitalista, devido aos seus efeitos perversos de concentração de renda e aumento das desigualdades, surgindo a agricultura familiar como uma alternativa para a superação desses problemas.

\section{A Atuação do Fundo Nacional de Desenvolvimento da Educação no apoio à agricultura familiar}

O papel do FNDE, como órgão responsável pela coordenação do PNAE, é fundamental para a manutenção e cumprimento da legislação relativa ao incentivo ao Desenvolvimento Local Integrado e Sustentável, apoiando os projetos de aquisição de alimentos da agricultura familiar.

Sua atuação em nível nacional por meio de capacitação dos conselheiros de alimentação escolar, gestores públicos e profissionais dessa área, além das ações de monitoramento, fiscalização e esclarecimento de dúvidas, permite que as diretrizes das resoluções expedidas pelo órgão, entre elas a de apoio ao pequeno produtor, sejam cumpridas.

O conhecimento acumulado e a proximidade cada vez maior com a sociedade civil organizada possibilitam a veiculação de idéias e de soluções locais que podem ser aproveitadas em outros municípios brasileiros. Além disso, ao estabelecer que o cardápio contenha alimentos básicos e recomendar o uso de produtos regionais, o FNDE induz o respeito à cultura alimentar local e ao uso de produtos in natura, típicos da agricultura familiar.

Em 2009, a alimentação escolar passou por significativas mudanças legais. Em janeiro foi aprovada a Medida Provisória $\mathrm{n}^{\mathrm{o}}$ $455^{[16]}$ que estabeleceu uma legislação para o atendimento à alimentação escolar, convertida na Lei $\mathrm{n}^{\mathrm{o}} 11.947^{[17]}$ em 16 de junho. No mês seguinte, o PNAE, por meio da Resolução FNDE/CD $\mathrm{n}^{\mathrm{o}} 38^{[18]}$, passou a contemplar as alterações da nova legislação e as normas para seu cumprimento.

Esta estabeleceu, no âmbito do PNAE, entre outras novidades, $\mathrm{o}$ atendimento a toda Educação Básica, ao incluir o Ensino Médio e a Educação de Jovens e Adultos; mudanças na estrutura e mandato do Conselho de Alimentação Escolar - CAE; e a obrigatoriedade das Entidades Executoras utilizarem, no mínimo, $30 \%$ dos recursos financeiros transferidos pelo FNDE, com dispensa do processo licitatório, para aquisição de gêneros alimentícios diretamente da Agricultura Familiar e do Empreendedor Familiar Rural ou suas organizações, priorizando assentamentos da reforma agrária e comunidades tradicionais indígenas e quilombolas.

A aquisição da Agricultura Familiar com recursos do PNAE já vigorava desde 2008, por meio do PAA ${ }^{[19]}$, e passou a ter um percentual definido com a lei $11.947^{[17]}$, com limite de R $\$ 9.000,00$ por Agricultor ou Empreendedor Familiar por ano, desde que: seja emitido documento fiscal, haja $o$ 
fornecimento regular e constante dos gêneros alimentícios e sejam respeitadas as exigências higiênico-sanitárias vigentes definidas pelos órgãos competentes. Os preços também devem ser compatíveis com os do mercado local segundo os termos da Resolução FNDE/CD n ${ }^{-}$ $38 / 09$ [18] que estabeleceu todos os procedimentos para a compra. Os municípios têm 180 dias para se adaptarem à nova regra, considerada uma das principais conquistas da nova lei.

\section{Panorama do programa de aquisição de alimentos da agricultura familiar}

A instituição do PAA, por meio do art. 19 da lei $\mathrm{n}^{\mathrm{o}}$ 10.696, de 02/07/2003 [20], representou a criação de um mecanismo inovador de incentivo direto à agricultura familiar, produtores assentados da reforma agrária e pequenas agroindústrias, por meio da compra de sua produção.

Inserido no contexto das políticas estruturantes do Programa Fome Zero ${ }^{[21]}$, seu objetivo central foi possibilitar a venda, para a administração pública, de produtos agropecuários oriundos de agricultores familiares que se enquadrassem nos grupos $\mathrm{A}$ ao D do PRONAF, com Declaração de Aptidão ao Pronaf - DAP. Incluiu também os acampados da reforma agrária, os agroextrativistas, os quilombolas, as famílias atingidas por barragens, trabalhadores rurais sem terra acampados (definidos de acordo com a Portaria MDA no 111 , de 20/11/2003 ${ }^{[22]}$ ), comunidades indígenas, pescadores artesanais, aquicultores familiares e produtores familiares em condições especiais, desde que autorizados pela $\mathrm{CONAB}{ }^{[23]}$. Os beneficiários produtores começaram recebendo $\mathrm{R} \$ 2.500,00$ /produtor/ano e, até agosto de 2009, o valor foi de $\mathrm{R} \$ 3.500,00 /$ produtor/ ano, sendo eles produtores individuais ou grupos informais e formais (Cooperativas e Associações) com pelo menos $80 \%$ dos sócios/afiliados enquadrados como agricultores familiares com acesso ao PRONAF ${ }^{[24,25]}$.

A implementação tem sido efetivada por um Grupo Gestor, coordenado pelo MDS e composto pelo Ministério da Fazenda - MF, Ministério da Agricultura, Pecuária e Abastecimento - MAPA, Ministério do Planejamento, Gestão e Orçamento - MPOG e Ministério do Desenvolvimento Agrário MDA ${ }^{[20]}$, cuja atribuição é definir as medidas necessárias para a operacionalização do Programa. A execução, no âmbito federal, é feita pelo MDA, MDS e MAPA, este último por meio da CONAB. Além desses, o Programa conta com os "Gestores Locais": Cooperativas e Associações de produtores familiares, Prefeituras Municipais, Conselhos Sociais locais e outras entidades locais que ajudam a operá-lo no município dando apoio logístico, de planejamento, de controle e de fiscalização. A fonte de recursos é o MDS, por meio do Fundo Nacional de Erradicação da Fome e da Pobreza e, a partir de 2006, também o MDA ${ }^{[20]}$.

Em sua concepção inicial englobava dois mecanismos de atuação e sete modalidades. Quanto aos mecanismos, dividese em: a) formação de estoques, podendo ser substituída, em algumas situações, por liquidação financeira; e b) doação simultânea, que representa a compra e o imediato atendimento direto às demandas de suplementação alimentar e nutricional de pessoas em risco de insegurança alimentar. A 
forma de atender essa população é o fornecimento de gêneros para instituições governamentais ou não-governamentais que desenvolvam trabalhos publicamente reconhecidos ou Programas sociais do governo, como por exemplo, a merenda escolar.

Quanto às modalidades, ao longo dos anos elas foram sendo reestruturadas e agrupadas. Neste artigo, a modalidade de interesse é aquela que atende a alimentação escolar, atualmente chamada "Compra com Doação Simultânea", formada por duas "antigas" modalidades, a Compra Antecipada Especial da Agricultura Familiar - CAEF, operada pela CONAB, e a Compra Direta Local da Agricultura Familiar - CDLAF, operada pelos Governos Estaduais e Prefeituras Municipais ${ }^{[26]}$. Embora bastante similares, as duas modalidades ainda são executadas com estratégias diferenciadas, sendo a primeira realizada por meio de análise direta do órgão e a segunda por meio de edital. A merenda é a principal demandante desse mecanismo, representando, no mínimo, $50 \%$ do total da aquisição ${ }^{7}$.

Como citado anteriormente, em 2008 o PAA passou a contar com mais uma fonte de recursos com a edição do Decreto $\mathrm{n}^{\mathrm{0}}$ 6.447/08 [19], que estabeleceu a compra de alimentos da agricultura familiar com os recursos do PNAE, transferidos pelo FNDE, e a inclusão do Ministério da Educação - MEC, no grupo gestor do PAA ${ }^{[27]}$.

Em setembro de 2009, em função da grande evolução do PAA, novos valores e regras ampliaram a possibilidade de ganhos do agricultor familiar. Além do limite de R\$9.000,00/DAP/ano para o PNAE, o agricultor familiar passou a acessar o PAA na modalidade de compra com doação simultânea (CAEAF ou CDLAF) com o limite de $\mathrm{R} \$ 4.500,00 / \mathrm{DAP} / \mathrm{ano}$, além de outras três modalidades não associadas à alimentação escolar, de forma cumulativa, que chegam a um limite de até $\mathrm{R} \$ 8.000,00 / \mathrm{DAP} / \mathrm{ano}^{[28]}$. Isso significa que o agricultor familiar pode garantir a comercialização de sua produção com uma venda de até R \$17.000,00/DAP/ano a preços justos, o que representará um grande incremento e capitalização para o segmento.

\section{Sistematização e descrição dos mecanismos de apoio à agricultura familiar nos municípios por meio da alimentação escolar}

No âmbito local, podem ser destacados projetos e ações das Prefeituras municipais que, a partir das demandas da merenda escolar, apoiaram a agricultura familiar tanto do ponto de vista comercial, quanto técnico e organizacional.

Para avaliar essas experiências foi utilizada a base do Prêmio Gestor Eficiente da Merenda Escolar - 2006. A partir da análise desse banco de dados foi criada uma tipologia dos mecanismos que as Prefeituras vêm utilizando para incentivar a pequena produção por meio da merenda escolar, definindo-se 12 diferentes formas de apoio. O Quadro 1 mostra a descrição dessa categorização.

\footnotetext{
7 Entrevista realizada com Silvio Isopo Porto, Diretor de Logística e Gestão Empresarial da CONAB, em 20/11/2006 e com Rachel Cossich Furtado, Coordenadora Geral de Apoio à Vigilância Alimentar e Nutricional, do MDS, em 23/11/2006.
} 
Quadro 1. Categorização das Formas de Apoio ao Produtor Familiar por Meio da Merenda Escolar

\begin{tabular}{|c|c|}
\hline $\begin{array}{l}\text { Formas de Apoio ao Produtor Familiar } \\
\text { pela Merenda Escolar }\end{array}$ & Descrição \\
\hline $\begin{array}{l}\text { 1. Aquisição de Produtor Individual e/ou } \\
\text { Cooperativa/Associação }\end{array}$ & $\begin{array}{l}\text { Aquisição, pela Prefeitura, por meio de compra } \\
\text { simples ou licitação, de produtos de pequenos } \\
\text { produtores rurais, individuais ou organizados em } \\
\text { associações ou cooperativas. }\end{array}$ \\
\hline 2. Participação no PAA & $\begin{array}{l}\text { Participação dos agricultores familiares locais em } \\
\text { alguma das modalidades do PAA cujos produtos são } \\
\text { direcionados para a merenda escolar do município } \\
\text { (Compra com doação simultânea). }\end{array}$ \\
\hline $\begin{array}{l}\text { 3. Apoio em Infra-Estrutura Produtiva e } \\
\text { Logística }\end{array}$ & $\begin{array}{l}\text { Cessão de máquinas agrícolas; fornecimento e/ou } \\
\text { subsídio para compra de insumos (sementes, mudas, } \\
\text { adubo, etc.); e/ou apoio logístico na entrega dos } \\
\text { produtos. }\end{array}$ \\
\hline 4. Promoção da Produção Rural Familiar & $\begin{array}{l}\text { Criação de Programas municipais de geração de renda } \\
\text { e auto-sustentabilidade da família agrícola por meio de } \\
\text { arranjos e parcerias da Secretaria da Educação com a } \\
\text { Empresa de Assistência Técnica e Extensão Rural - } \\
\text { EMATER, Sindicato de Produtores Rurais, Serviço } \\
\text { Nacional de Aprendizagem Rural - SENAR, } \\
\text { Conselho Municipais de Desenvolvimento Rural - } \\
\text { CMDR e Secretarias da Agricultura, da Ação Social, } \\
\text { ou de Desenvolvimento Rural. }\end{array}$ \\
\hline $\begin{array}{l}\text { 5. Valorização e Divulgação Cultural da } \\
\text { Agricultura Familiar }\end{array}$ & $\begin{array}{l}\text { Realização de eventos que valorizem a agricultura } \\
\text { familiar, agroecologia; introdução do tema no } \\
\text { currículo escolar; divulgação do tema nas escolas; } \\
\text { escolas agrícolas; e/ou visitas a pequenos produtores } \\
\text { rurais. }\end{array}$ \\
\hline $\begin{array}{l}\text { 6. Apoio e Capacitação para Produção de } \\
\text { Hortaliças, Frutas, Leite, Pequenos } \\
\text { Animais e Piscicultura }\end{array}$ & $\begin{array}{l}\text { Incentivo à produção de hortifrutigranjeiros e pesca } \\
\text { (produtos tradicionais da agricultura familiar), por } \\
\text { meio da criação de hortas comunitárias; e/ou formação } \\
\text { profissional e cursos nessa área. }\end{array}$ \\
\hline $\begin{array}{l}\text { 7. Apoio e Capacitação para Produção } \\
\text { Orgânica, Fitoterápica, Agroecológica, de } \\
\text { Mel, de Alimentos Funcionais e de } \\
\text { Produtos Regionais }\end{array}$ & $\begin{array}{l}\text { Incentivo à produção de produtos típicos da pequena } \\
\text { produção por atenderem a um nicho de mercado e } \\
\text { seguirem práticas culturais agroecológicas. }\end{array}$ \\
\hline
\end{tabular}




\begin{tabular}{|l|l|}
\hline $\begin{array}{l}\text { 8. Capacitação Organizacional; Cursos de } \\
\text { Profissionalização e Empreendedorismo; } \\
\text { e/ou Orientações sobre Comercialização }\end{array}$ & $\begin{array}{l}\text { Capacitação na área administrativa, contábil e } \\
\text { comercial dos pequenos produtores rurais locais por } \\
\text { meio de parcerias com SEBRAE, EMATER, } \\
\text { Sindicatos e/ou outras Secretarias, orientando } \\
\text { principalmente sobre o processo licitatório, emissão de } \\
\text { nota fiscal e outros documentos. }\end{array}$ \\
\hline $\begin{array}{l}\text { 9. Estímulo e Capacitação para } \\
\text { Cooperativismo e Associativismo }\end{array}$ & $\begin{array}{l}\text { Apoio técnico e organizacional para a formação ou } \\
\text { reestruturação de cooperativas ou associações de } \\
\text { pequenos produtores. }\end{array}$ \\
\hline $\begin{array}{l}\text { 10. Estímulo e Capacitação para a } \\
\text { Agroindustrialização Familiar }\end{array}$ & $\begin{array}{l}\text { Estímulo à criação de pequenas agroindústrias com o } \\
\text { apoio da vigilância sanitária e outras instituições, } \\
\text { viabilizando a construção de fábricas em locais } \\
\text { reduzidos; concessão de incentivos e/ou benefícios } \\
\text { para a ampliação ou geração de novos } \\
\text { empreendimentos. }\end{array}$ \\
\hline $\begin{array}{l}\text { 11. Fortalecimento Político e Institucional } \\
\text { da Agricultura Familiar pela Prefeitura }\end{array}$ & $\begin{array}{l}\text { Criação de Secretarias Municipais específicas para a } \\
\text { promoção do segmento, cadastramento de produtores } \\
\text { rurais, regularização fundiária; e/ou garantia da } \\
\text { comunicação sobre editais de licitação. }\end{array}$ \\
\hline $\begin{array}{l}\text { 12. Apoio em Infra-Estrutura de } \\
\text { Beneficiamento e para Regularização de } \\
\text { Exigências Sanitárias }\end{array}$ & $\begin{array}{l}\text { Municipal e orientações da Vigilância Sanitária aos } \\
\text { criaça e organização do Serviço de Inspeção } \\
\text { agricultores sobre as exigências sanitárias dos } \\
\text { produtos comercializados. }\end{array}$ \\
\hline
\end{tabular}

Fonte: Elaboração da autora a partir de dados do Prêmio Gesto Eficiente da Merenda Escolar - 2006.

Do total das 610 inscrições em 2006, 250 municípios implementaram uma ou mais ações associando a merenda escolar à pequena produção local, sendo que 187 Prefeituras realizaram uma única forma de apoio, 39 realizaram duas formas, 14 realizaram três formas, 9 realizaram quatro formas e uma Prefeitura realizou cinco das formas apresentadas.

Com relação à classificação das formas de apoio, separando-se as aquisições dos outros tipos de apoio, tem-se que: 176 Prefeituras compraram diretamente do produtor individual, 55 Prefeituras compraram de associações/cooperativas, 35 Prefeituras participaram do PAA para atender a merenda e 75 Prefeituras implementaram Programas ou ações não comerciais, de sua iniciativa.

Os dados do Prêmio mostram que as 250 Prefeituras que incentivaram a pequena produção realizaram um total de 346 ações, como se observa na Tabela 1. A maior parte das ações (60,4\% do total) foi "Aquisição de Produtor Rural Individual ou Organizado em Cooperativas/Associações" por meio de licitação ou, sendo valores até $\mathrm{R} \$ 8.000,00$, 
com sua dispensa e cotação de no mínimo três fornecedores ${ }^{[29]}$. As outras ações mais significativas foram: "Participação no PAA"
(10,1\%); "Apoio em Infra-estrutura produtiva e logística" (5,5\%); e "Promoção da Produção Rural Familiar" (4,6\%).

Tabela 1. Formas de Apoio ao Produtor Familiar por Meio da Merenda Escolar de Municípios Inscritos no Prêmio Gestor Eficiente da Merenda Escolar - 2006, em 2005.

\begin{tabular}{|c|c|c|}
\hline \multirow{2}{*}{ Formas de Apoio ao Produtor Familiar pela Merenda Escolar } & \multicolumn{2}{|c|}{ Ações } \\
\hline & Número & $\%$ \\
\hline Aquisição de Produtor Individual e/ou Cooperativa/Associação & 209 & 60,4 \\
\hline Participação no PAA & 35 & 10,1 \\
\hline Apoio em Infra-Estrutura Produtiva e Logística ${ }^{1}$ & 19 & 5,5 \\
\hline Promoção da Produção Rural Familiar ${ }^{2}$ & 16 & 4,6 \\
\hline Valorização e Divulgação Cultural da Agricultura Familiar ${ }^{3}$ & 12 & 3,5 \\
\hline $\begin{array}{l}\text { Apoio e Capacitação para Produção de Hortaliças, Frutas, Leite, Pequenos } \\
\text { Animais e Piscicultura }\end{array}$ & 12 & 3,5 \\
\hline $\begin{array}{l}\text { Apoio e Capacitação para Produção Orgânica, Fitoterápica, Agroecológica, de } \\
\text { Mel, de Alimentos Funcionais e de Produtos Regionais }\end{array}$ & 11 & 3,2 \\
\hline $\begin{array}{l}\text { Capacitação Organizacional; Cursos de Profissionalização e Empreendedorismo; } \\
\text { e/ou Orientações sobre Comercialização }{ }^{4}\end{array}$ & 09 & 2,6 \\
\hline Estímulo e Capacitação para Cooperativismo e Associativismo & 08 & 2,3 \\
\hline Estímulo e Capacitação para a Agroindustrialização Familiar & 06 & 1,7 \\
\hline Fortalecimento Político e Institucional da Agricultura Familiar pela Prefeitura ${ }^{5}$ & 05 & 1,4 \\
\hline $\begin{array}{l}\text { Apoio em Infra-Estrutura de Beneficiamento e para Regularização de Exigências } \\
\text { Sanitárias }{ }^{6}\end{array}$ & 04 & 1,2 \\
\hline Total de Ações & 346 & 100,0 \\
\hline
\end{tabular}

Fonte: Elaboração da autora a partir de dados do Prêmio Gesto Eficiente da Merenda Escolar - 2006.

Nota: ${ }^{1)}$ Cessão de Máquinas Agrícolas; Fornecimento e/ou Subsídio para Compra de Insumos (Sementes, Mudas, Adubo, Etc.); e/ou Apoio Logístico na Entrega dos Produtos.

2) Criação de Programas Municipais de Geração de Renda e Auto-sustentabilidade da Família Agrícola.

3) Realização de Eventos que Valorizem a Agricultura Familiar, Agroecologia; Introdução do Tema no Currículo Escolar; Divulgação do Tema nas Escolas; e/ou Visita a Pequenos Produtores Rurais.

4) Processo Licitatório, Emissão de NF e outros Documentos.

5) Criação de Secretarias, Cadastramento de Produtores, Regularização Fundiária, Garantia da Comunicação sobre Editais de Licitação e Etc.

6) Criação e organização do Serviço de Inspeção Municipal e orientações da Vigilância Sanitária aos agricultores.

\section{Análise da modalidade do PAA utilizada na alimentação escolar}

O PAA, embora seja uma ação do Governo Federal, foi inserido juntamente com as ações locais por também representar, na maioria dos municípios, uma decisão da Prefeitura, que pode apoiar o Programa em todas as suas fases, desde o levantamento dos beneficiários ofertantes e demandantes até $\mathrm{o}$ recebimento dos gêneros pelas entidades beneficiadas.

A partir da pesquisa e das entrevistas verificou-se que a modalidade do PAA utilizada para merenda escolar além de contribuir para reforçar a quantidade de alimentos nas escolas e creches e garantir produtos de qualidade, tem contribuído para a 
manutenção dos agricultores no campo por meio da garantia da renda a preços justos.

Embora a falta de profissionalização e baixo volume de oferta de produtos sejam problemas bastante mencionados pelos administradores públicos que alegam que os pequenos produtores não conseguem entregar os produtos na quantidade necessária, ou não apresentam as especificações sanitárias e os selos de inspeção necessários para a comercialização, o Programa tem incentivado os produtores familiares a aprimorarem a gestão da sua lavoura e/ou criação, diversificando sua produção ou mesmo abrindo pequenas agroindústrias, a fim de agregar valor aos seus produtos. Foi o que aconteceu em Concórdia, Santa Catarina, onde existiam, em 2006, 34 pequenas agroindústrias familiares na Cooperativa de Produção Agroindustrial Familiar de Concórdia COPAFAC, sendo que várias delas entregavam produtos para a merenda, como, por exemplo, o açúcar mascavo e o melado.

O presidente da Cooperativa e membro do Conselho Municipal de Segurança Alimentar e Nutricional - COMSEA de Concórdia ${ }^{8}$ contou que os produtores que participaram do $\operatorname{PAA}^{9}$ (desde 2003) tiveram um ganho de renda e puderam variar a produção, mas que o maior benefício foi a profissionalização, pois com a obrigação de entregar semanalmente produtos para a merenda, passaram a gerir melhor o seu

\footnotetext{
8 Entrevista realizada com Alziro Corassa, conselheiro do COMSEA de Concórdia/SC e presidente da Cooperativa de Produção Agroindustrial Familiar de Concórdia, em 03/11/2006. 9 Em Concórdia a Cooperativa de Produção Agroindustrial Familiar operou o PAA em $2003 \quad\left(1^{\circ}\right.$ programa $)$ com R\$111.000,00 e 46 produtores; em 2003/2004 com R $\$ 139.000,00$ e 59 produtores; em 2004/2005 com $\mathrm{R} \$ 175.000,00$ e 71 produtores; e em 2005/2006 com $\mathrm{R} \$ 240.000,00$ e 86 produtores (valores aproximados).
}

negócio. "Hoje somente $10 \%$ dos produtores têm resistência a se organizar. As pessoas perceberam que precisavam disso", afirma o presidente. Esse aprendizado levou também a um fortalecimento da Cooperativa e uma aproximação com a administração municipal. Antes o transporte dos gêneros era um problema e no final de 2006 a Prefeitura recebeu recursos do Programa Fome Zero para a compra de um veículo para transportar os produtos ponto a ponto.

Em diversas situações verifica-se que o Programa tem ajudado vários pequenos produtores a se organizarem em forma de Associações ou Cooperativas, ou promovido o fortalecimento das instituições já existentes. É o caso do município de Joinville ${ }^{10}$, onde 82 produtores agroecológicos, que possuem o selo Ecovida ${ }^{11}$, conseguiram viabilizar a Cooperativa de Produtores Agroecológicos de Joinville - COPAVILLE por causa do PAA. A instituição era antes uma Associação com poucos produtores que comercializavam seus produtos em suas propriedades e atualmente, além de participar do Programa, conquistaram várias parcerias e estão se organizando para atingir novos mercados. No entanto, os extensionistas locais afirmaram que embora seja importante que os recursos da merenda permaneçam no município, em termos de renda os valores do $\mathrm{CAEAF}^{12}$, mesmo sendo de recebimento $100 \%$ garantido por serem

\footnotetext{
10 Entrevista realizada com Rivelino Simas e Jacson José Tavares, técnicos da Fundação 25 de julho, órgão da Assistência Técnica e Extensão Rural de Joinville/SC, e com Acácio Schereder, produtor familiar e tesoureiro da Cooperativa de Produtores Agroecológicos de Joinville - COPAVILLE, em 30/08/2007.

11 Certificação de Produção Agroecológica gratuita feita pela Rede participativa Ecovida, que engloba consumidores e produtores distribuídos em 200 núcleos e está presente nos estados do Paraná, Santa Catarina e Rio Grande do Sul.

${ }^{12}$ Modalidade do PAA utilizada em Joinville/SC.
} 
antecipados, são usados pelos agricultores familiares como uma proteção em momentos de dificuldade, não sendo suficientes para garantir sua sobrevivência.Essa parece ser uma percepção comum entre os segmentos envolvidos, pois gestores do Programa $^{13}$ acreditam que, apesar dos recursos terem aumentado ano a ano, a demanda ainda é muito superior aos recursos existentes, tendo sido observadas recusas de propostas de participação com valores superiores a $\mathrm{R} \$ 200.000,00$, no caso da CONAB, e a necessidade de seleção de municípios e estados prioritários nos editais do MDS, não sendo possível atender a totalidade dos inscritos que atendem às exigências.

Pode-se apontar um problema de gestão das políticas públicas que se relaciona a essa questão da falta de recursos: eles existem, mas muitas vezes não são consumidos. Isso se deve, em parte, porque algumas Entidades Executoras (municípios e estados) não podem firmar convênios devido às suas contas não estarem em dia ou com os projetos prontos para receberem o dinheiro. Além disso, há problemas gerenciais dentro e entre os ministérios, destacando-se como um dos principais o fato do Ministério da Fazenda concentrar a liberação dos recursos na segunda metade do ano para garantir a meta do superávit primário, o que leva os ministérios a prepararem seus gastos durante o primeiro semestre para utilizá-los no segundo. Esses problemas apareceram tanto no relatório do Tribunal de Contas da União - TCU, sobre as contas do Governo Federal de 2004, que

\footnotetext{
13 Entrevista realizada com Silvio Isopo Porto, Diretor de Logística e Gestão Empresarial da CONAB, em 20/11/2006 e com Rachel Cossich Furtado, Coordenadora Geral de Apoio à Vigilância Alimentar e Nutricional, do MDS, em 23/11/2006.
}

apontou que 53\% dos Programas analisados não alcançaram as metas físicas previstas para o ano, como também em levantamento feito no Sistema Integrado de Administração Financeira do Governo Federal, no qual se constatou que, até o fim de outubro de 2005, $70 \%$ dos Programas do Orçamento Federal não haviam desembolsado metade do valor autorizado para ser gasto naquele ano ${ }^{[30]}$.

Analisando-se a base do Prêmio Gestor Eficiente da Merenda Escolar - 2006, ano de referência 2005, verificou-se que das 610 inscrições de Prefeituras de todo o Brasil, 35 declararam ter participado do PAA para atender a merenda. No entanto, essa baixa participação, apenas 5,7\% do total, pode ter outras causas. Várias Prefeituras desconhecem a existência do Programa, além da falta de comunicação verificada entre as Secretarias Municipais, haja vista que alguns municípios que têm o PAA não o utilizam para a merenda porque a Secretaria responsável pelo PNAE não sabe que isso é possível.

Outro ponto a ser considerado é o desconhecimento do termo "PAA". A partir de conversas com funcionários da merenda e das respostas nos formulários, observa-se que o Programa é mais conhecido pelos apelidos que as modalidades assumem nos locais (compra local, compra direta, compra antecipada, compra direta do produtor rural, etc.) do que por seu nome ou sigla, e que os próprios gestores locais do PAA não têm informações sobre as diferentes modalidades que $\mathrm{o}$ Programa possui. Muitos também confundem o órgão executor e acreditam que é um Programa municipal da Secretaria da Agricultura ou de Desenvolvimento, ou que é do governo do Estado em parceria com a 
Empresa de Assistência Técnica e Extensão Rural - EMATER.

Esse último motivo ocorre particularmente na modalidade CDLAF, que é o convênio do MDS com os governos municipais ou estaduais na compra com doação simultânea, porque, via de regra, o órgão que coordena o Programa localmente é a EMATER, que é estadual. Quando a modalidade é executada pela CONAB fica mais clara a participação federal por ser um órgão dessa esfera de governo.

Essas confusões em grande parte refletem a estrutura complicada do Programa, com várias modalidades, diferentes estratégias e atuação desarticulada das múltiplas instâncias que o compõe. Somente no nível governamental estão presentes cinco ministérios, além de estados e municípios, com interesses e práticas diversas, o que é comum na transversalidade das ações, porém que requer ao mesmo tempo um grande poder de coordenação.

Entre as regiões, a que mais se destacou em participação no PAA foi a região Sul, com 16 municípios, onde há um predomínio daqueles com menos de 20 mil habitantes, seguido do Sudeste com 8 municípios, e do Nordeste com 7 municípios. No Norte e Centro-Oeste o número foi inexpressivo. Em termos de distribuição nas unidades da federação, de um total de 26 estados que participaram do Prêmio, apenas em 12 foi verificada a participação no PAA para merenda. Em termos absolutos, os estados com maior número de municípios participantes foram Paraná, Minas Gerais e Santa Catarina, sendo que o primeiro teve oito
Prefeituras entre 40 inscritas (20\%); o segundo teve sete Prefeituras entre 112 inscritas (6,3\%); e o terceiro teve 6 Prefeituras entre 47 inscritas $(12,8 \%)$. A unidade da federação com maior participação relativa entre inscritos e participantes do PAA foi o Maranhão (42,9\%, 3 municípios entre 7 inscritos) e a com menor participação foi São Paulo $(0,8 \%, 1$ município entre 112 inscritos).

Um outro motivo que pode ter levado à baixa participação dos municípios, além dos descritos anteriormente, é de cunho político. Um exemplo disso é o depoimento do presidente da COPAFAC de Concórdia que afirmou que o PAA só "sai" se a Prefeitura está interessada e que muitas Prefeituras da região (cerca de $30 \%$ dos municípios) não quiseram adotá-lo porque enxergavam um viés ideológico no Programa, principalmente associado ao Programa Fome Zero.

\section{Projetos de apoio à agricultura familiar desenvolvidos pelas prefeituras municipais}

As ações comerciais, como a compra de produtos ou a participação no PAA, representaram a maior parte por serem práticas mais simples, e que envolveram diretamente a merenda escolar ao fornecer os alimentos para o preparo das refeições. Já o apoio à infraestrutura produtiva e logística, assim como o desenvolvimento de Programas de geração de renda para os pequenos produtores, apesar de terem sido bem menos comuns do que as práticas comerciais, foram ações mais dirigidas, em que a Prefeitura investiu para efetivar o apoio e tiveram um caráter complementar às aquisições. 
Alguns municípios como Araxá, em Minas Gerais, e Quissamã, no Rio de Janeiro, criaram legislações municipais que antecederam o PAA na idéia da compra dirigida à pequena produção. Em Quissamã, foi firmado um convênio entre a Cooperativa Mista dos Produtores Rurais de Quissamã e a Prefeitura por meio das leis n⿳0 0638/01 e $n^{\underline{0}}$ 0658/01, em que a Prefeitura se comprometeu a comprar água de coco engarrafada para a merenda escolar até 2011. Em 2005, foram distribuídas, semanalmente, 33.200 garrafas de $300 \mathrm{ml}$ de água de coco. Já em Araxá, a Prefeitura instituiu o PRÓ HORTA Programa Municipal de Incentivo à Produção de Hortifrutigranjeiros de Araxá, na forma de lei ${ }^{[31]}$, adquirindo legumes e verduras para a merenda escolar da Associação dos Produtores de Hortifrutigranjeiros - Asshorgran, de Araxá. A idéia do Programa surgiu há 15 anos, quando o governo municipal, por meio da Secretaria da Agricultura, juntamente com o Procon e a EMATER, estabeleceram uma parceria com a associação no intuito de manter a qualidade da merenda escolar e evitar o êxodo do pequeno produtor rural.

De forma geral as compras de produtores familiares representaram uma pequena parcela dos gastos do PNAE nos municípios. Entre aqueles que fizeram aquisição direta dos agricultores individuais ou organizados em associações ou cooperativas, o maior montante adquirido foi de R\$ $600.000,00$ e o menor foi de $\mathrm{R} \$ 100,00$, sendo que em média o valor da compra foi de $\mathrm{R} \$$ $43.835,65$, o que representou cerca de $9,0 \%$ do valor total médio dos gastos com alimentos para a merenda escolar.
Desse total de municípios (209), 24\% das Prefeituras também fizeram outra ação de incentivo à agricultura familiar. É o caso do município de Dois Irmãos, no Rio Grande do Sul, que adquiriu, em 2005, R $\$ 17.419,90$ (12,2\% do total dos gastos com alimentos na merenda) de produtores locais e também realizou visitas da coordenação da merenda escolar e do CAE aos locais de produção; orientações aos produtores sobre documentação, processo licitatório e produção (por meio da EMATER/RS-ASCAR Associação Sulina de Crédito e Assistência Rural e do Sindicato dos Trabalhadores Rurais e da Vigilância Sanitária); e fortalecimento do Serviço de Inspeção Municipal - SIM, abrangendo uma parcela maior de pequenos produtores locais, tornando seus gêneros aptos do ponto de vista sanitário ${ }^{[32]}$.

$\mathrm{Na}$ região do município de Dois Irmãos praticou-se uma das ações contida na forma de apoio "Valorização e Divulgação Cultural da Agricultura Familiar". A partir da demanda dos Conselhos Municipais de Desenvolvimento Rural - CMDRS e dos CAE de alguns municípios, realizou-se um interessante estudo de resgate do itinerário de desenvolvimento daquela localidade, bem como um diagnóstico da realidade e potencialidades, que apontou a riqueza do patrimônio ambiental/paisagístico e a importância histórica da agricultura familiar para o desenvolvimento sócio-econômico do Vale do Rio dos Sinos, onde existem 13.500 famílias de agricultores que vivem da atividade agropecuária ${ }^{[32]}$. Uma outra Prefeitura dessa localidade, Rolante, que também participou do Prêmio e do referido estudo, incentivando a montagem da rota 
turística aos produtores locais, declarou ter adquirido $\mathrm{R} \$ 2.995,95$ (4,0\% do total dos gastos com alimentos na merenda) dos produtores locais e apoiado a legalização da agroindústria familiar como uma de suas prioridades.

Outro exemplo desse tipo de iniciativa foi o projeto Muxima, em Santo Antônio de Jesus, na Bahia. $\mathrm{O}$ projeto visou à regionalização da merenda escolar, vinculando Desenvolvimento Regional e cultura local. Uma de suas ações foi a "curricularização", na prática, do projeto, no âmbito das disciplinas constantes das Diretrizes Curriculares do Ensino Fundamental, com contextualização de exemplos no conjunto de cada uma das matérias.

Quando a forma de apoio foi a participação no PAA, verifica-se um aumento no número de Prefeituras que também fizeram outra ação de incentivo à agricultura familiar, chegando a cerca de $60 \%$ delas. Na Prefeitura de Guaira, no Paraná, por exemplo, a Diretora da Alimentação Escolar e nutricionista ${ }^{14}$ contou que, a partir de uma pesquisa de sua autoria, de 2005, sobre possíveis projetos que pudessem auxiliar no aumento de recursos para melhoria da merenda escolar, encontrou o PAA e convidou a CONAB e mais dez municípios da região para uma reunião de esclarecimentos sobre o Programa. Depois de várias reuniões com órgãos locais foram desenvolvidos projetos, pelo Departamento de Alimentação Escolar, para quatro Associações/Cooperativas locais (Associação Guairense de Apicultores, Associação da Feira dos Pequenos Agricultores de Guaira,
Associação de Alimentos Orgânicos e COOPERLEITE - Cooperativa Agroindustrial de Guaira) que foram aprovados pelo Comitê Fome Zero do município. Em 2007, os recursos destinados à merenda escolar representaram $75 \%$ do valor total do PAA no ano.

Entre outras iniciativas a Prefeitura realizou a criação do Serviço de Inspeção Municipal, uma das ações mais importantes e necessárias para a inclusão da pequena produção em vários municípios brasileiros, pois dá as condições para a regularização sanitária dos produtos, fundamental para a venda para a alimentação escolar. Segundo Belik ${ }^{[33]}$, a própria Prefeitura pode simplificar o processo de certificação do SIM, como, por exemplo, certificando a produção local dentro de matadouros municipais em boas condições, ou, no caso de hortifrutigranjeiros, junto a equipamentos atacadistas administrados pelo poder público, como mercados municipais, centrais de abastecimento ou centrais de distribuição ${ }^{[34]}$.

Além do SIM, a Prefeitura de Guaira destinou recursos municipais para a melhoria da infra-estrutura de produção e beneficiamento (energia elétrica, maquinário, entre outros); articulou a participação da EMATER; cadastrou produtores familiares; e apoiou a comercialização. No caso da Associação de produtores orgânicos, a Prefeitura fez uma parceria com a ONG

\footnotetext{
${ }^{14}$ Entrevista realizada com Vanessa Bragato Richiter, Diretora da Alimentação Escolar e nutricionista de Guaira/PR, em 30/07/2007.
} 
Centro de Acolhimento Orientação e Proteção ao Adolescente - CAOPA, para a contratação de um engenheiro agrônomo exclusivo da instituição.

Já o presidente da COOPERLEITE ${ }^{15}$ relatou que a entidade começou como uma Associação e, devido ao impedimento para emissão de nota fiscal, iniciaram um processo de transformação para cooperativa que recebeu expressivo apoio do governo local. Os produtores participaram de um curso ministrado pela EMATER sobre cooperativismo e outro pelo Serviço Nacional de Aprendizagem Rural - SENAR, para qualificação e promoção da família rural. Além do curso, a EMATER também ajudou os produtores a comprarem um resfriador de 2.500 litros e uma empacotadora de leite, o que permitiu aumentar a produção e tornar a organização independente de outro grande laticínio da região. Por sua vez, a Prefeitura ajudou aportando recursos para alterar a energia de monofásica para trifásica e para a reforma do maquinário do laticínio. $\mathrm{O}$ presidente relatou que a organização dos produtores mudou bastante: "no começo faltava leite para entregar, eles ligavam para a Prefeitura e combinavam a mudança no cardápio. Mas hoje não acontece mais. Devido a mudanças administrativas a entrega está controlada".

Por outro lado, as formas de apoio que menos se destacaram entre as Prefeituras foram o estímulo e capacitação para a agroindustrialização familiar, o fortalecimento político e institucional, e o apoio em infra-

15 Entrevista realizada com Ailton Simião, presidente da COOPERLEITE de Guaira/PR, em 03/08/2007. estrutura de beneficiamento e para regularização de exigências sanitárias, apesar, deste último, ser considerado um dos pontos chaves para comercialização com a Prefeitura, como citado anteriormente, e não demandar recursos elevados.

De forma distinta, o fomento à agroindústria requer uma organização e investimento maior por parte da gestão pública, que por vezes não tem essa capacidade, embora seja uma das ações mais significativas para agregar valor aos produtos familiares e levar o segmento à auto-sustentabilidade financeira. Nos municípios onde ocorreu, traduziu-se pela escolha de gêneros industrializados típicos da pequena produção, como macarrão caseiro e queijo colonial, bem como pela instituição de Programas de promoção da agroindústria local por meio da concessão de incentivos e subsídios para geração de novos empreendimentos e ampliação dos existentes. Quanto ao fortalecimento político, apesar de também ser uma medida pouco dispendiosa e depender principalmente de vontade política e uma boa estrutura administrativa, também esteve presente em poucos municípios. As principais medidas foram o apoio à legalização dos agricultores como produtores rurais, criação de Secretarias voltadas especificamente ao desenvolvimento desse grupo social, e apoio ao acesso e à regularização fundiária.

A análise de todas as ações por região e tamanho de municípios inscritos revelou que a grande maioria delas ocorreu no Sudeste (108), Sul (103) e Nordeste (75). Em termos de distribuição das atividades, observa-se que a região Sul desenvolveu quase todas as iniciativas, com exceção do "Fortalecimento 
Político e Institucional da Agricultura Familiar pela Prefeitura", e, na região Sudeste, não se registraram casos de "Estímulo e Capacitação para Cooperativismo e Associativismo" e "Apoio em Infra-Estrutura de Beneficiamento e para Regularização de Exigências Sanitárias", sendo que esta última só ocorreu no Sul e Nordeste. O Centro-Oeste foi a região que experimentou a menor diversificação de formas de apoio, concentrando-se naquelas associadas à comercialização dos produtos, seguindo o comportamento das outras regiões.

Quanto ao tamanho dos municípios, apesar do apoio do governo local à agricultura familiar ser mais comum entre os de pequeno porte, por terem normalmente maior número de minifúndios e uma base econômica assentada na agricultura, a maior parte das iniciativas do Norte, Nordeste e Sudeste localizou-se nos municípios de médio porte, o que pode estar relacionado com Prefeituras mais organizadas e com mais recursos para investir. Já no Centro-Oeste, o número entre médios e pequenos se equilibrou e no Sul a maioria foi de pequenos municípios, o que é uma característica dessa região (exemplos: Horizontina/RS, São João do Oeste/SC, e Fernandes Pinheiro/PR com, respectivamente, $17.699,5.789$ e 6.602 habitantes).

No Norte, um exemplo dessa distribuição é o município de Macapá, capital do Amapá, com 355.408 habitantes, que desenvolve o projeto Caixa Escolar desde 2002, no qual se fez uma merenda regionalizada por meio do repasse das verbas diretamente às escolas (gestão escolarizada), possibilitando a racionalização dos gastos. Essa estratégia acabou com a compra de enlatados e permitiu que algumas escolas adicionassem o café da manhã como refeição complementar, porque as compras passaram a ser feitas em quantidades menores, sem intermediários, o que reduziu o preço e a perda por deterioração. Além disso, a Prefeitura recomendou que as escolas adquirissem os produtos, e também serviços, nas cercanias das escolas, desde que fossem elaborados três orçamentos, para impulsionar a economia local. Esse projeto foi uma reedição de uma tentativa frustrada de implantação em 2000, que acabou sendo abandonada porque as escolas não tiveram organização suficiente e faltaram alimentos para a merenda. No projeto de 2002 a Prefeitura promoveu um treinamento em gestão escolar para diretores, professores e pais de alunos que receberam noções sobre administração e prestação de contas ${ }^{[35]}$.

Já no Nordeste, segundo o Secretário Municipal de Educação ${ }^{16}$, o município de São Miguel, no Rio Grande do Norte, com cerca de 22.000 habitantes, participou em 2005 do PAA, na modalidade CDLAF (convênio MDS e estado) e destinou cerca de $70 \%$ desses recursos à merenda. Além disso, cadastrou cerca de 500 pequenos produtores da região em um sistema da Secretaria de Desenvolvimento Rural e Meio Ambiente; cedeu máquinas para preparo do solo no período chuvoso; e forneceu sementes para os agricultores cadastrados. Também ajudou na reorganização da cooperativa de pequenos produtores fundada nos anos 70, que se transformou na Associação de Produtores Hortifrutigranjeiros de São Miguel, com 29 pequenos produtores, com a finalidade de fornecer para a cozinha central da Prefeitura. 
Neste caso, o movimento foi oposto ao que normalmente ocorre em outros estados (associações transformando-se em cooperativas), como explicou o presidente da organização ${ }^{17}$, pois verificaram, com o apoio da Prefeitura, que já havia uma associação no estado (para a qual há menos burocracia na abertura) que emitia nota fiscal e por isso conseguiram uma brecha na legislação da Fazenda Estadual.

No Sudeste alguns exemplos de Prefeituras de médio porte são Araxá-MG, citada anteriormente, com 84.689 habitantes; Governador Valadares-MG, com 247.131 habitantes, onde a Prefeitura desenvolveu um Programa de apoio à implantação de duas agroindústrias familiares; e Olímpia-SP, com 46.667 habitantes, onde havia um projeto em parceria com o SEBRAE e a Casa da Agricultura para capacitação de 18 pequenos produtores em empreendedorismo e produção de hortas orgânicas, além do fornecimento de sementes e compra dos produtos.

\section{Conclusão}

Um dos pontos principais na avaliação das ações de apoio à agricultura familiar foi a integração entre a comunidade e os vários segmentos governamentais e sociais. Quando há um trabalho conjunto, em que os interesses são negociados e a Prefeitura tem visão e vontade política, acreditando que tais ações visam à desconcentração de renda e ao fortalecimento da economia local, é possível realizar projetos com resultados positivos.

\footnotetext{
${ }^{16}$ Entrevista realizada com Luis Marcos Alves Costa, Secretário Municipal de Educação de São Miguel/RN, em 07/08/2007.

17 Entrevista realizada com Francisco Lindolfo Teófilo, presidente da Associação de Produtores de Hortifrutigranjeiros de São Miguel/RN, em 08/08/2007.
}

Isto não significa inexistência de conflitos, ou soluções rápidas e fáceis para os problemas estruturais e operacionais, mas sim uma disposição para o enfrentamento, em que se reconhece a necessidade do associativismo ou cooperativismo para $\mathrm{o}$ atendimento às demandas que se almejam, desenvolvendo a noção de empreendedorismo entre os agricultores familiares.

$\mathrm{Na}$ maioria dos casos, os benefícios citados referiram-se ao fortalecimento da economia local pela retenção do capital gasto pela Prefeitura no PNAE dentro da própria região; aumento e diversificação da produção; fortalecimento institucional; redução do êxodo rural pelo ânimo renovado dos pequenos produtores, principalmente no caso do PAA; abertura de novos mercados após o início das vendas para a Prefeitura; investimento na atividade produtiva; garantia de renda e aumento da qualidade de vida; e aumento da formalização dos agricultores familiares por meio do cadastramento e adesão a Programas e participação em Cooperativas/Associações.

Tais resultados derivaram de uma série de ações e Programas implementados ou apoiados pela Prefeitura Municipal - quase sempre em parceria com órgãos do estado, do Governo Federal, de outras entidades locais ou regionais - a partir da demanda da merenda escolar e do atendimento à sua legislação.

Foram classificados doze diferentes tipos de iniciativas de apoio à agricultura familiar por meio da alimentação escolar, em 250 municípios, e constatou-se que o PNAE pode ser um propulsor do Desenvolvimento Local. 
A maior parte das ações ocorreu nas regiões Sudeste, Sul e Nordeste, sendo na região Sul a maior diversificação de práticas e no Centro-Oeste a menor. Quanto ao tamanho populacional, os municípios de médio porte foram os mais ativos no Norte, Nordeste e Sudeste, e no Sul estiveram mais presentes os pequenos.

As iniciativas que apareceram com maior freqüência estiveram ligadas a alguma forma de aquisição dos alimentos. Vários exemplos de compra direta de produtos da agricultura familiar já vinham sendo desenvolvidos por Prefeituras com legislações municipais específicas, muitas vezes questionáveis do ponto de vista da lei de licitações.

Com a entrada do PAA em 2003, abriu-se uma exceção a essa lei, na forma de um Programa federal, implementando-se uma política de aquisição abrangente que, entre outros objetivos, promoveu a vinculação da compra do segmento mais desprotegido da agropecuária e agroindústria com a demanda de alimentos pela merenda escolar e pessoas em risco de insegurança alimentar por meio de uma rede de instituições locais e/ou estaduais da área social e técnica.

O PAA avançou no sentido da transversalidade de ações e interação entre os ministérios, níveis de governo e instituições. Promoveu também o aumento dos recursos aportados para a merenda escolar e a melhoria da qualidade da alimentação com o uso de mais gêneros hortifrutigranjeiros, muitas vezes derivados da produção orgânica/ agroecológica. Do ponto de vista dos produtores familiares, permitiu a elevação da renda dessas famílias; ganhos na organização técnica e gerencial da produção familiar; aumento da diversidade dos produtos, com a consequente abertura de mercado e autonomia; e aumento das iniciativas baseadas no desenvolvimento sustentável do ponto de vista social e ambiental por meio do crescimento da produção agroecológica e orgânica.

Em que pesem os benefícios advindos do Programa, devem-se apontar também as falhas que impediram o PAA de ter uma maior abrangência. Em termos de objetivos e órgãos/instituições envolvidos, o PAA tornouse muito complexo e, muitas vezes, pouco reconhecido pelos beneficiários potenciais.

Além disso, embora tenha aumentado o volume de recursos, o Programa enfrentou uma série de problemas de gestão intra e interministeriais que impossibilitaram o completo atendimento da demanda e sub-aproveitamento das verbas disponíveis. Considerando que o PAA é um dos Programas estruturantes do Fome Zero, faz-se necessária a elaboração de um planejamento orçamentário capaz de atender o público fornecedor, que por vezes vê seus projetos indeferidos, e o público demandante sem o recebimento dos produtos.

A partir de 2009, a nova legislação da alimentação escolar e do PAA formaram um importante arcabouço legal para promover o fortalecimento da agricultura familiar. No entanto, para atingir a meta de articulação do PNAE de forma sinérgica com ações promotoras de Desenvolvimento Local e redução da desigualdade social, é necessária a integração das políticas públicas, viabilizando os mecanismos de implementação da nova lei pelas secretarias responsáveis pelo PNAE e 
desburocratizando e aumentando os recursos destinados a Programas como o PAA fazendo-os chegar no momento certo ao produtor, bem como, fortalecendo institucionalmente o segmento e promovendo sua capacitação técnica e organizacional.

\section{Referências Bibliográficas}

[1] Fonseca, WS. Da. Bases da Alimentação do Escolar. Coleção Ensaio e Debate Alimentar, Rio de Janeiro, Vol. 1, Série Gigante, SAPS, 1953.

[2] Stefanini, MLR. Merenda Escolar: História, Evolução e Contribuição no Atendimento das Necessidades Nutricionais da Criança. São Paulo: USP/ FSP, Tese de Doutoramento, 1998.

[3] FNDE. Dados estatísticos. 2009. Disponível em: < http://www.fnde.gov.br/ >. Acesso em 23/10/2009.

[4] FNDE. Resolução FNDE/CD/ $\mathrm{n}^{0}$ 32, de 10/08/2006: altera per capita para pré-escola e ensino fundamental e para creches e escolas indígenas e localizadas em áreas remanescentes de Quilombos.

[5] Benko, G (1995). Economia, Espaço e Globalização na Aurora do Século XXI. $3^{\mathrm{a}}$ ed. São Paulo: Editora Hucitec: (Annablume, 2002), 1995.

[6] MDA. Apresentação - Crédito. 2006. Disponível em: <http://www.mda.gov.br/saf/ index. php?sccid $=811>$. Acesso em $02 / 12 / 2006$.

[7] Azzoni, CR. Teoria da Localização: uma Análise Crítica. A Experiência de Empresas Instaladas no Estado de São Paulo. São Paulo, Instituto de Pesquisas Aplicadas - FEA-USP, 1982.

[8] Diniz, CC. A Questão Regional e as Políticas Governamentais no Brasil. Belo Horizonte: Texto pra Discussão $\mathrm{n}^{-}$159, CEDEPLAR/FACE/UFMG, 2001.
[9] Schejtman A. \& Berdegué, J.A. Desarrollo Territorial Rural, Santiago, RIMISP, Chile, 2003.

[10] Putnan, D.R. Comunidade e Democracia: experiência da Itália moderna. Rio de Janeiro: FGV, 1996.

[11] Brandão, C. A. Localismos, Mitologias e Banalizações na Discussão do Processo de Desenvolvimento. In: VII Encontro Nacional de Economia Política e II Colóquio Latino Americano de Economistas Políticos. CuritibaPR. Anais... maio, 2002.

[12] Sorj, B. Estado e classes sociais na agricultura brasileira. Rio de janeiro: Ed. Guanabara, 1986.

[13] Belik, W. Pronaf: Avaliação da operacionalização do programa. In: CAMPANHOLA, C. \& GRAZIANO da SILVA, J. (org). O Novo Rural Brasileiro Políticas Públicas. Jaguariúna: Embrapa, volume 4, pg. 93-116, 2000.

[14] Silva, E. R. A. Programa Nacional de Fortalecimento da Agricultura Familiar: Relatório Técnico das Ações Desenvolvidas no Período 1995/1998. Brasília: IPEA, texto para discussão 664, 1999.

[15] Kühn, D.D. (2002) Agricultura Familiar: uma Alternativa para o Desenvolvimento Rural Sustentável. In: Anais do XL Congresso Brasileiro de Economia e Sociologia Rural, Passo Fundo-RS. Anais... julho, 2002.

[16] Brasil, Medida Provisória $\mathrm{n}^{\mathrm{o}}$ 455, de 28/01/2009: dispõe sobre o atendimento da alimentação escolar e do Programa Dinheiro Direto na Escola aos alunos da educação básica, altera a Lei no 10.880, de 9 de junho de 2004, e dá outras providências. 
[17] Brasil, Lei nº 11.947, de 16/06/2009: dispõe sobre o atendimento da alimentação escolar e do Programa Dinheiro Direto na Escola aos alunos da educação básica.

[18] FNDE. Resolução FNDE/CD/ n⿳0 38, de 16/07/2009: dispõe sobre o atendimento da alimentação escolar aos alunos da educação básica no Programa Nacional de Alimentação Escolar - PNAE.

[19] Brasil, Decreto $n^{-0} 6.447$, de 07/05/2008: Regulamenta o art. 19 da Lei no 10.696, de 2 de julho de 2003, que institui o Programa de Aquisição de Alimentos.

[20] Brasil, Lei $\mathrm{n}^{\mathrm{o}}$ 10.696, de 02/07/2003: institui o Programa de Aquisição de Alimentos.

[21] Instituto Cidadania. Fome Zero - Uma proposta de política de segurança alimentar para o Brasil. São Paulo, 2001.

[22] MDA. Portaria $n^{-0} 111$, de 20/11/2003: inclui os trabalhadores rurais sem terra acampados se incluem no Programa de Aquisição de Alimentos - PAA.

[23] MDS. Programa de Aquisição de Alimentos - PAA. s/d. Documento interno - V Encontros dos Povos do Cerrado. Brasília-DF, 2006.

[24] CONAB. Manual de Operação da CONAB-MOC. s/d. Disponível em: $<\mathrm{http}: / /$ www.conab.gov.br/conabweb $>$. Acesso em 27/11/2006.

[25] CONAB. Programa de Aquisição de Alimentos - PAA. Documento interno. Brasília-DF, 2006.

[26] MDS. Programa de Aquisição de Alimentos - PAA. Compra direta local da agricultura familiar - CDLAF: manual de orientação ao proponente. Brasília-DF, 2004.
[28] Brasil, Decreto n⿳o 6.959, de 15/09/2009: dá nova redação à legislação que institui o Programa de Aquisição de Alimentos.

[29] TCU. Cartilha para Conselheiros do Programa Nacional de Alimentação Escola http://www.planalto.gov.br/Consea/exec/noticia s.cfm?cod=20432>. Acesso em 01/02/2009.

[29] TCU. Cartilha para Conselheiros do Programa Nacional de Alimentação Escolar PNAE.Tribunal de Contas da União. 2.ed.Brasília: TCU, 6 ${ }^{\text {a }}$ Secretaria de Controle Externo, 2004.

[30] Portal Exame. 2005. Corta Onde não Pode, Gasta Onde não Deve. Disponível em: $<$ http://portalexame.abril.com.br/revista/exa me/edicoes/0855/economia/m0078516. html $>$. Acesso em 25/02/2008.

[31] Prefeitura Municipal de Araxá/MG, Lei $n^{\circ}$ 3.651, 08/05/00: instituiu o PRÓ HORTA Programa Municipal de Incentivo à Produção de Hortifrutigranjeiros de Araxá.

[32] EMATER/RS-ASCAR \& FETAG \& Prefeituras Municipais dos Rios dos Sinos e Paranhana/ Encosta da Serra. Manual de Alimentação Escolar. Porto Alegre, 2005.

[33] Belik, W. O Programa Nacional de Alimentação Escolar como Instrumento de Promoção do Desenvolvimento Local. s/d. Disponível em: $<$ http://www.escoladegestores.inep.gov.br/dow nloads/artigos/PNAE/PNAE $>$. Acesso em 20/06/2006.

[34] Apoio Fome Zero. Manual de Gestão Eficiente da Merenda Escolar. São Paulo, $3^{\mathrm{a}}$ edição, 2005.

[35] Cidades Vivas, Fartura no recreio. Partido dos Trabalhadores e Editora Fundação Perseu Abramo, 2004.

[27] CONSEA. Programa ganha parceria de mais um ministério. 2008. Disponível em: < http://www.planalto.gov.br/Consea/exec/noticia s.cfm?cod=20432>. Acesso em 01/02/2009. 